\begin{tabular}{|c|c|c|c|c|}
\hline$<5$ & $0.032^{*}$ & $\begin{array}{l}3.812(1.125- \\
12.912)\end{array}$ & $0.024^{*}$ & $\begin{array}{l}3.340(1.174- \\
9.502)\end{array}$ \\
\hline$\geq 5-10$ & $0.001^{*}$ & $\begin{array}{l}0.140(0.042- \\
0.471)\end{array}$ & 0.072 & $\begin{array}{l}0.589(0.330- \\
1.049)\end{array}$ \\
\hline$\geq 10-20$ & 0.077 & $\begin{array}{l}0.479(0.212- \\
1.083)\end{array}$ & 0.174 & $\begin{array}{l}0.665(0.369- \\
1.198)\end{array}$ \\
\hline >20 (reference) & & 1.000 & & 1.000 \\
\hline \multicolumn{5}{|l|}{ Height } \\
\hline$\leq$ Mean & $0.001^{*}$ & $\begin{array}{l}0.223(0.096- \\
0.519)\end{array}$ & $0.042^{*}$ & $\begin{array}{l}0.594(0.360- \\
0.982)\end{array}$ \\
\hline >Mean (reference) & & 1.000 & & 1.000 \\
\hline $\begin{array}{l}\text { Donor-recipient gender } \\
\text { mismatch }\end{array}$ & 0.643 & $\begin{array}{l}1.170(0.603- \\
2.272)\end{array}$ & 0.878 & $\begin{array}{l}0.964(0.605- \\
1.536)\end{array}$ \\
\hline Transplant episode & 0.458 & $\begin{array}{l}1.320(0.634- \\
2.750)\end{array}$ & 0.868 & $\begin{array}{l}1.049(0.600- \\
1.832)\end{array}$ \\
\hline $\begin{array}{l}\text { Donor recipient weight } \\
\text { ratio }\end{array}$ & 0.687 & $\begin{array}{l}0.982(0.897- \\
1.074)\end{array}$ & 0.774 & $\begin{array}{l}1.009(0.950- \\
1.071)\end{array}$ \\
\hline Warm ischemia time (min) & 0.427 & $\begin{array}{l}1.014(0.980- \\
1.049)\end{array}$ & 0.163 & $\begin{array}{l}1.018(0.993- \\
1.043)\end{array}$ \\
\hline Cold ischemia time & 0.821 & $\begin{array}{l}1.014(0.899- \\
1.144)\end{array}$ & 0.871 & $\begin{array}{l}1.007(0.927- \\
1.093)\end{array}$ \\
\hline \multicolumn{5}{|l|}{ Year of surgery } \\
\hline Before 2005 (reference) & & 1.000 & & 1.000 \\
\hline $2005-2010$ & 0.295 & $\begin{array}{l}0.674(0.322- \\
1.411)\end{array}$ & 0.242 & $\begin{array}{l}0.726(0.425- \\
1.242)\end{array}$ \\
\hline After 2010 & $0.004^{*}$ & $\begin{array}{l}0.254(0.101- \\
0.638)\end{array}$ & $0.001^{*}$ & $\begin{array}{l}0.381(0.211- \\
0.687)\end{array}$ \\
\hline Invasive ventilation & $0.012^{*}$ & $\begin{array}{l}2.899(1.268- \\
6.631)\end{array}$ & 0.061 & $\begin{array}{l}1.894(0.972- \\
3.691)\end{array}$ \\
\hline
\end{tabular}

Abstract P42 Table 2 Multivariate cox regression analysis of risk factors for death and graft loss after PLT

\begin{tabular}{|c|c|c|c|c|}
\hline & \multicolumn{2}{|c|}{ Patient death } & \multicolumn{2}{|c|}{ Graft Loss } \\
\hline & $p$ & HR (95\%C.I) & $p$ & HR $(95 \%$ C.I) \\
\hline \multicolumn{5}{|l|}{ Age in years } \\
\hline $0-5$ months & 0.943 & $\begin{array}{l}6541.074(0.0- \\
\left.1.8 \times 10^{108}\right)\end{array}$ & 0.239 & $\begin{array}{l}5.143(0.336- \\
78.712)\end{array}$ \\
\hline $6-11$ months & 0.949 & $\begin{array}{l}2555.491(0.0- \\
\left.7.0 \times 10^{107}\right)\end{array}$ & 0.622 & $\begin{array}{l}1.693(0.209- \\
13.731)\end{array}$ \\
\hline $1-4$ year & 0.204 & $0.273(0.037-2.023)$ & 0.484 & $\begin{array}{l}0.591(0.135- \\
2.581)\end{array}$ \\
\hline $5-12$ year & 0.088 & $0.370(0.118-1.160)$ & 0.439 & $\begin{array}{l}0.733(0.334- \\
1.609)\end{array}$ \\
\hline$\geq 13$ year(reference) & & 1.000 & & 1.000 \\
\hline \multicolumn{5}{|l|}{ Graft type } \\
\hline Whole(reference) & & 1.000 & & - \\
\hline Technical variant & 0.705 & $1.229(0.423-3.573)$ & & - \\
\hline $\begin{array}{l}\text { Technical variant } \\
\text { LD }\end{array}$ & 0.085 & $4.663(0.810-26.858)$ & & - \\
\hline \multicolumn{5}{|l|}{ Category } \\
\hline CLD (reference) & & 1.000 & & 1.000 \\
\hline ALF & 0.639 & $0.709(0.168-2.985)$ & 0.400 & $\begin{array}{l}0.618(0.202- \\
1.895)\end{array}$ \\
\hline ALF on top of CLD & 0.984 & $0.000(-)$ & 0.976 & $0.000(-)$ \\
\hline Tumor & 0.160 & $2.477(0.700-8.769)$ & 0.929 & $\begin{array}{l}1.044(0.404- \\
2.697)\end{array}$ \\
\hline Metabolic & 0.948 & $0.000\left(0.0-2.7 \times 10^{130}\right)$ & 0.391 & $\begin{array}{l}0.415(0.056- \\
3.100)\end{array}$ \\
\hline Re-transplantation & 0.853 & $1.128(0.315-4.044)$ & 0.131 & $\begin{array}{l}0.467(0.173- \\
1.255)\end{array}$ \\
\hline
\end{tabular}

\begin{tabular}{|c|c|c|c|c|}
\hline \multicolumn{5}{|l|}{ Weight(kg) } \\
\hline$<5$ & 0.951 & $\begin{array}{l}0.001(0.0- \\
\left.1.582 \times 10^{101}\right)\end{array}$ & 0.778 & $\begin{array}{l}0.627(0.024- \\
16.179)\end{array}$ \\
\hline$\geq 5-10$ & 0.932 & $\begin{array}{l}0.001(0.0- \\
\left.7.352 \times 10^{99}\right)\end{array}$ & 0.567 & $\begin{array}{l}0.581(0.090- \\
3.739)\end{array}$ \\
\hline$\geq 10-20$ & 0.965 & $1.037(0.208-5.172)$ & 0.425 & $\begin{array}{l}1.524(0.542- \\
4.287)\end{array}$ \\
\hline$>20$ (reference) & & 1.000 & & 1.000 \\
\hline \multicolumn{5}{|l|}{ Height } \\
\hline$\leq$ Mean & 0.847 & $0.838(0.140-5.019)$ & 0.552 & $\begin{array}{l}0.656(0.163- \\
2.634)\end{array}$ \\
\hline$>$ Mean (reference) & & 1.000 & & 1.000 \\
\hline Year of surgery & & & & \\
\hline $\begin{array}{l}\text { Before } 2005 \\
\text { (reference) }\end{array}$ & & 1.000 & & 1.000 \\
\hline $2005-2010$ & 0.430 & $0.695(0.281-1.716)$ & 0.619 & $\begin{array}{l}0.855(0.461- \\
1.585)\end{array}$ \\
\hline After 2010 & $0.003^{\star}$ & $0.112(0.027-0.471)$ & $0.015^{*}$ & $\begin{array}{l}0.397(0.188- \\
0.836)\end{array}$ \\
\hline $\begin{array}{l}\text { Invasive } \\
\text { ventilation }\end{array}$ & 0.492 & $1.637(0.402-6.672)$ & 0.237 & $\begin{array}{l}1.877(0.662- \\
5.324)\end{array}$ \\
\hline
\end{tabular}

graft type, category, era of transplant and invasive ventilation. Univariate analysis for graft survival showed that the following variables had a significant $(\mathrm{p}<0.05)$ impact on graft survival: patient age, patient weight, patient height, category, and era of transplant. Multivariate statistical analysis of Patient and graft Survival showed that the only significant factor for graft and patient survival is the era of transplant where patients transplanted after 2010 has significantly higher recipient and graft survival.

Summary This study, spanning over about 20 years, represents one of the biggest UK based PLT single centre reports. Only significant factor for patient and graft survival was era of transplant with PLT after 2010 has significantly better patient and graft survival.

Conclusion Building experience has substantial effect on patient and graft survival. Traditional view of worse outcomes of smaller candidates should be changed especially in high volume centres with prolonged experience.

\section{P43 PROVISION OF BIOLOGICS IN SECONDARY CARE SETTING 5 YEARS ON: HOW ARE WE DOING? A SERVICE EVALUATION OF CURRENT COHORT INCLUDING PATIENT FEEDBACK}

${ }^{1}$ Angela Radford, ${ }^{2}$ Joyce Youssef, ${ }^{1}$ Shveta Chana. ${ }^{1}$ Milton Keynes University Hospital; ${ }^{2}$ Buckingham University

\subsection{6/flgastro-2021-bspghan.52}

Introduction/Background Treatment with anti-TNF $\alpha$ agents for paediatric patients with moderate to severe IBD has received increasing regulatory approvals since 2006. Treatment with Adalimumab and Infliximab was made available at Milton Keynes University Hospital, a secondary care setting in the Thames Valley region, following design of a shared care protocol in 2016. The service is resourced by local PeGHAN Consultant, Community Nursing team, Day Care unit and Pharmacy provisions supported by tertiary clinicians. 
Aim We set out to establish both the efficacy of the service and levels of patient satisfaction by conducting a survey of our current cohort of 12 IBD patients living in Milton Keynes and receiving treatment with biologics at our unit.

Subjects and Methods Our survey included the evaluation of data from electronic patient records (EPR) and telephone interviews. All patients have experience of the local service although three are presently on a regimen only available at the tertiary centre.

We looked at several aspects of their care including current choice and length of biologic treatment, evidence of remission, occurrence of adverse reactions, monitoring parameters and outpatient follow up arrangements.

Our telephonic patient questionnaire focused on whether families felt they were given sufficient information about treatment, the impact of receiving treatment locally and overall satisfaction with the service.

Results Of our 12 patients with IBD, 2 were diagnosed with Ulcerative Colitis and 10 with Crohn's disease. All are children of school age with an age range from 7 to 17.5 years.

9 children are eligible for local treatment, 7 of them receive Adalimumab injections and 2 children are treated with Infliximab infusions. The 3 children treated with Vedolizumab or Ustekinumab have previously received at least one other biologic locally. Treatment duration ranges from 2- 49 months on their current biologic, with a mean duration of 16.5 months.

6 children started their treatment at MKUH, 3 at Oxford but continued at MKUH. The remaining 3 started at Oxford to continue locally but went back to Oxford due to treatment failure. Initial biologic therapy had to be switched in 6 children due to suboptimal response. All families reported their child as now clinically well. Only 5 children achieved Calprotectin levels below $200 \mu \mathrm{g} / \mathrm{g}$. The mean CRP was 1.4 . Monitoring is done regularly with quarterly reviews at the joint IBD clinic.

All families feel they were given adequate information about treatment and accessible contact points for queries. Formal training was given to all families administering Adalimu$\mathrm{mab}$ at home by local community nursing team. Easy access to all health care professionals involved in the service was especially praised and appreciated. Parents feel the service is patient centred and individualised. There were no serious adverse events. Families described that local access meant less disruption to their child's lifestyle and education.

Summary and conclusion Treatment with biologics at secondary care hospital is safe, effective and contributes significantly to patient satisfaction.

Families feel well supported and appreciate the personalised care and accessibility of the service.

\section{P44 QUALITY IMPROVEMENT: IMPACT OF IMPLEMENTATION OF REFERRAL PATHWAY FOR ABDOMINAL PAIN ON INITIAL ASSESSMENT TIME, BLOOD INVESTIGATIONS REQUESTED, IMAGING PERFORMED AND EVENTUAL OUTCOME}

${ }^{1}$ Hina Rizvi, ${ }^{2}$ Chui Lai, ${ }^{1}$ Vijay Iyer, ${ }^{1}$ Anjum Gandhi. ${ }^{1}$ Birmingham Heartlands Hospital; ${ }^{2}$ Birmingham Women's Hospital

10.1136/flgastro-2021-bspghan.53
Background In our trust, historically paediatric patients presenting with abdominal pain raising suspicion of appendicitis were referred to surgeons and assessed in the Paediatric Assessment Unit. These patients faced long wait times for management plan by surgeons:

- covering theatres/adult wards and intensive care

- waiting for blood and imaging investigation results before finalizing a plan.

This led to delays and affected flow of patients through the PAU and the ward capacity. The Paediatric team decided to bring about a change in the abdominal pain referral pathway by proposing to see all patients referred with abdominal pain and refer to surgeons if deemed appropriate.

We collected data over 2 periods: 2018 and 2020, with the implementation of the new pathway in 2019

Aim To assess:

- Time to first review by a team (paediatric vs surgical)

- Percentage of patients

- With abdominal pain referred to each team

- Who had blood tests and imaging requested by each team

- Discharged, observed, referred and admitted by each team

Methods

- Sample period: 4 weeks in 2018 and 6 weeks in 2020

- Inclusion criteria: all paediatric patients referred with abdominal pain to PAU

- Exclusion criteria: anyone with previous appendectomy or re attending.

- Data collection: retrospective.

- Case notes: reviewed for referral record, review times, and initial diagnosis

- Electronic patient management system: reviewed for blood test and imaging investigation requested and discharge summaries

Results Primary care referral rose from $36 \%$ in 2018 to $47 \%$ in 2020 with a concurrent shift in ED referral from 53\% to $37 \%$ in 2020 showing the effect of the new pathway. $26 \%$ of referrals were made to Paediatric team in 2018 vs $87 \%$ in 2020

Majority of patients were seen within 4 hours by the Paediatric team in both episodes $86 \%$ vs $85 \%$. There was very slight improvement in Surgical team review time $78 \%$ vs $80 \%$.

There was an increase in discharges to $58 \%$ by the surgical team in 2020 from $35 \%$ in 2018. However, we also saw the increase in referral by the Paediatricians to Surgeons from $7 \%$ to $33 \%$

There was an impressive drop in blood investigation requested by the Surgical team from 90\% to 58\%. Requests for imaging by surgical teams declined from $33 \%$ to $17 \%$.

$88 \%$ of the referred patients with abdominal pain had medical diagnosis at discharge and did not need any surgical intervention

Summary Re-auditing after implementing new abdominal pathway shows:

- Overall patient flow through PAU has improved as more patients are being discharged.

- Appropriate reduction in laboratory investigation 2018 vs 2020 (both by surgical team from $90 \%$ to $58 \%$ and Paediatric team from $43 \%$ to $17 \%$ ) 